\title{
Biodegradation of DDE and DDT by Bacterial Strain Stenotrophomonas sp. DXZ9
}

Hui Xie*, Lusheng Zhu*, Jun Wang, Jinhui Jiang and Jinhua Wang

Key Laboratory of Agricultural Environment in Universities of Shandong, National Engineering Laboratory for Efficient Utilization of Soil and Fertilizer Resources, College of Resources and Environment, Shandong Agricultural University, Taian 271018, PR China

\begin{abstract}
Bacterial strain DXZ9, which is able to degrade DDE, was isolated from the sludge of a pesticide factory. The sludge had been contaminated with DDT during an enrichment culture technique. The bacteria was identified as a Stenotrophomonas sp. The effects of various factors, such as $\mathrm{pH}$, temperature and the concentration of the initial substrate on the degradation portion of DDE were investigated. The results showed that the DDE biodegradation proportion was $39.4 \%$ at the end of the 5 th day, and the biodegradation proportion increased slightly and reached $41.9 \%$ at the end of the 10th day. Optimally, the $\mathrm{pH}$, the concentration of the substrate, and the cultivation temperature were $7,10 \mathrm{mg} / \mathrm{l}$ and $30^{\circ} \mathrm{C}$, respectively, within 5 days and based on experimental optimization. DDT, the parent compound of DDE, could also be degraded by this bacterium; the biodegradation proportion of DDT was $55.0 \%$ and $57.6 \%$ at the end of the 5th and 10th days, respectively. The metabolites were analyzed by gas chromatography/mass spectrometry (GC/MS). DDT is dehydrochlorinated to DDE by bacterium DXZ9, and the metabolites of DDE were multipler undefined substances. These results indicate that DXZ9 has the ability to metabolize DDE and its parent compound, and it shows tremendous potential for use in field applications for the bioremediation of contaminated soil.
\end{abstract}

Keywords: Biodegradation; Organochlorine pesticides; Persistent organic pollutants; Toxic metabolites; Bioremediation

\section{Introduction}

DDT is listed as a priority persistent organic pollutant (POP) by the United Nations' Environment Program in the Stockholm Convention [1]. DDT was classified in the precedent-controlled product directory as a compound with high pollutant and high environmental risk in China. DDT is an environmental endocrine disruptor and its residue and associated risk are still an issue of great contention due to its toxicity, persistence and bioaccumulation [2]. Dichloro-2,2-bis(4-chlorophenyl) ethylene (DDE), which is one of the toxic and primary metabolites of 1,1,1-trichloro-2,2-bis(4-chlorophenyl) ethane DDT [3,4], is stable, easily bioaccumulated [5] and difficult to biologically degrade in nature. The literature has reported that DDE residue was detected in agricultural workers from Bolivia. The concentration of DDE in the serum and in their lipids was $19.7 \mathrm{ng} / \mathrm{ml}$ and $4788.7 \mathrm{ng} /(\mathrm{g}$ lipid), respectively, and it was shown to induce proinflammatory molecules in the human peripheral blood mononuclear cells due to its toxicity [6]. Furthermore, DDE was shown to cause serious environmental problems [7]. Because DDT is persistent and degraded extremely slowly in the natural environment, the enhancement of its degradation by microorganisms has been popular in recent decades. Some bacteria and fungi were isolated from the environment, such as Clostridium sp. BXM [8], Pseudoxanthomonas jiangsuensis sp. Nov. [9], two white rot fungi [10], wood rot fungi [11] and litter-decomposing basidiomycetes [12]. Though there has been some studies in the literature that use microorganisms for the degradation of DDT, DDE has been reported to be more persistent than DDT in the environment and has caused serious environmental problems worldwide. Furthermore, the conversion of DDT to DDE by microorganisms has been termed a 'dead-end side reaction' [13], and there have been few reports on the biodegradation of DDE. A study of the bacterial degradation system of DDE is useful for the development of effective bioremediation technologies for DDE. Four degrading DDE strains have been reported, including three bacteria, Pseudomonas acidovorans M3GY [14], Terrabacter sp. DDE-1 [15], and Janibacter sp. TYM3221 [7,16], and one wood-rotting basidiomycete Phanerochaete chrysosporium [13]. p, $\mathrm{p}^{\prime}$-DDE is the predominant degradation product of DDT in soils, but it can also cause serious environmental problems.
To cope with this problem, it is very important to conduct studies on the biodegradation of DDE. The aim of the present study was the isolation and characterization of a Stenotrophomonas sp. DXZ9, which could not only degrade DDE but also degrade DDT. To our knowledge, this study is the first report of DDE degradation by Stenotrophomonas $s p$. It has been reported that the strain Stenotrophomonas sp. can degrade $\mathrm{HCH}$ and methyl parathion [17], acetamiprid [18] and chlorothalonil [19]. However, there has been no report of a Stenotrophomonas sp.-degrading DDE bacterium, which would be a better bioremediation technology for DDE contaminated sites than current methods.

\section{Materials and Methods}

\section{Media and chemicals}

DDE (99\% pure) and DDT (99\% pure) were purchased from Shenyang Research Institute of Chemical Industry, China. Acetone, petroleum ether $\left(60-90^{\circ} \mathrm{C}\right)$, n-hexane and ethyl acetate were analytical grade and were redistilled before being used in experiments.

\section{Enrichment and isolation of DDE-degrading bacteria}

The microorganisms were isolated from the sludge of a pesticide

*Corresponding authors: Hui Xie, Key Laboratory of Agricultural Environment in Universities of Shandong, National Engineering Laboratory for Efficien Utilization of Soil and Fertilizer Resources, College of Resources and Environment, Shandong Agricultural University, Taian 271018, PR China, Tel: 8242879; E-mail: huixie@sdau.edu.cn

Lusheng Zhu, Key Laboratory of Agricultural Environment in Universities of Shandong, National Engineering Laboratory for Efficient Utilization of Soil and Fertilizer Resources, College of Resources and Environment, Shandong Agricultural University, Taian 271018, PR China, Tel: 8242879; E-mail: lushzhu@sdau.edu.cn

Received July 30, 2017; Accepted August 03, 2017; Published August 15, 2017

Citation: Xie H, Zhu L, Wang J, Jiang J, Wang J (2017) Biodegradation of DDE and DDT by Bacterial Strain Stenotrophomonas sp. DXZ9. J Environ Anal Toxicol 7: 496. doi: $10.4172 / 2161-0525.1000496$

Copyright: $\odot 2017 \mathrm{Xie} \mathrm{H}$, et al. This is an open-access article distributed under the terms of the Creative Commons Attribution License, which permits unrestricted use, distribution, and reproduction in any medium, provided the original author and source are credited. 
Citation: Xie H, Zhu L, Wang J, Jiang J, Wang J (2017) Biodegradation of DDE and DDT by Bacterial Strain Stenotrophomonas sp. DXZ9. J Environ Anal Toxicol 7: 496. doi: 10.4172/2161-0525.1000496

Page 2 of 8

factory, which was contaminated with DDT during the enrichment culture technique, i.e., $\mathrm{MSM}\left(4.0 \mathrm{~g} \mathrm{NaNO}_{3}, 1.5 \mathrm{~g} \mathrm{KH}_{2} \mathrm{PO}_{4}, 0.005 \mathrm{~g} \mathrm{FeCl}_{3}\right.$, $0.01 \mathrm{~g} \mathrm{CaCl}_{2}, 0.2 \mathrm{~g} \mathrm{MgSO}_{4}$ and $0.5 \mathrm{~g} \mathrm{Na}_{2} \mathrm{HPO}_{4}$ in 1 liter of distilled water ( $\mathrm{pH}$ 7.0)) supplemented with $0.5 \%$ peptone was used in the experiment. The solid medium used for growing the consortium and the individual isolates consisted of $15 \mathrm{~g}$ of agar in 1 liter of distilled water ( $\mathrm{pH} 7.0$ ). The media was sterilized by autoclaving at $121^{\circ} \mathrm{C}$ for $20 \mathrm{~min}$ [20] and contained $50 \mathrm{mg} / \mathrm{l}$ of DDE, which was used as the training bacterium material. The culture was regularly transferred to fresh medium at weekly intervals and incubated on a $500 \mathrm{ml}$ Erlenmeyer flask on a rotary shaker $(160 \mathrm{r} / \mathrm{min})$ at $30^{\circ} \mathrm{C}$. After many transfers, a mixed microbial population system was established. This consortium was gradually acclimated to increasing concentrations of DDE from 50 to $100 \mathrm{mg} / \mathrm{l}$. The microbial consortium was maintained on an agar plate containing $50 \mathrm{mg} / \mathrm{l}$ of DDE. Six morphologically distinct bacterial strains were isolated from the sample, and the strain DXZ9 showed the highest degradation rate.

\section{Identification and classification of the strain DXZ9}

Physiological and biochemical identification of DXZ9 was achieved by referencing the "Common Bacterial Identification Manual" [21], examining its phenotypic morphology characteristics and comparing the $16 \mathrm{~S}$ rDNA of the sequence in GeneBank (NCBI). According to a homology comparison, the strain could be identified and classified.

\section{Biodegradation of DDE}

The strains were tested for their ability to degrade DDE. The strains grown in the minimal salts medium were harvested by centrifugation at $8,000 \mathrm{r} / \mathrm{min}$ for $10 \mathrm{~min}$, washed twice with sterile water, and resuspended in sterile water. For all experiments, a concentration of $10^{6}$ cells/l was used. Individual isolates were inoculated into replicate test tubes (tube culture) containing $5 \mathrm{ml}$ of MSM with $10 \mathrm{mg} / \mathrm{l}$ of DDE. The controls consisted of uninoculated medium. The samples were incubated at $30^{\circ} \mathrm{C}$ by shaking in the dark $(160 \mathrm{r} / \mathrm{min})$. After incubation for 3,5,7 and 10 days, the liquid medium cultures and bacterial colony were extracted with $5 \mathrm{ml}$ hexane for analysis by Shimadzu GC-14 gas chromatography; all experiments were replicated three times under the same condition. The method of research for studying the effect of $\mathrm{pH}$ and temperature on the biodegraded proportion of DDE $(10 \mathrm{mg} / \mathrm{l})$ and biomass determination was in accordance with the reported references [22]. To confirm the effect of different concentrations of DDE on the biodegraded proportion, the acclimated cells were inoculated into a basal medium containing different concentrations of DDE, ranging from 1 to $20 \mathrm{mg} / \mathrm{l}$. The test tubes were incubated at $30^{\circ} \mathrm{C}$ on a rotary shaker for 5 days.

\section{Analysis of residual DDE}

The external calibration method was used for the quantified determination of DDE, and the correlation coefficients of the calibration curves were all 0.999 . The standard solution of DDE was added in the culture solution of the minimal salts medium, and the concentrations of DDE were 1.0, 5.0, 10.0 and $20.0 \mathrm{mg} / \mathrm{l}$. Every added concentration was repeated six times and then analyzed using gas chromatography with GC-ECD. The recovery proportion of DDE in the culture solution of the minimal salts medium was $92.74 \%-93.38 \%$. Residual DDE was determined by gas chromatography equipped with a ${ }^{63} \mathrm{Ni}$ electron capture detector (ECD) and a 14\% cyanopropyl phenyl polysiloxane wide capillary column (OV-1701, $30 \mathrm{~m} \times 0.53 \mathrm{~mm} \times 1.0 \mu \mathrm{m}$, Australia). The initial GC operating conditions included an injector temperature of $230^{\circ} \mathrm{C}$, a detector temperature of $280^{\circ} \mathrm{C}$, and an oven temperature of $160^{\circ} \mathrm{C}$. The oven temperature was first increased to $220^{\circ} \mathrm{C}$ at a rate of $40^{\circ} \mathrm{C} / \mathrm{min}$ and then was increased to $250^{\circ} \mathrm{C}$ at a rate of $5^{\circ} \mathrm{C} \min$. The temperature was then maintained at $250^{\circ} \mathrm{C}$ for $2 \mathrm{~min}$. The samples $(1 \mu \mathrm{l}$ each) were injected in the splitless mode.

\section{Biodegradation of DDT}

To verify the degraded range of the strain, the acclimated cells were inoculated into a basal medium containing DDT with an initial concentration of $10 \mathrm{mg} / \mathrm{l}$ and an initial $\mathrm{pH}$ of 7.0; the test tubes were incubated at $30^{\circ} \mathrm{C}$ on a rotary shaker for 5 days, and the method of research was in accordance with the reported references [22].

\section{Extraction and determination of metabolites}

After incubation for 3, 5 and 10 days, the metabolites of p, $\mathrm{p}^{\prime}$-DDT and $\mathrm{p}, \mathrm{p}^{\prime}$-DDE were isolated from the supernatant of the grown cell suspensions incubated with p, $\mathrm{p}^{\prime}$-DDT and $\mathrm{p}, \mathrm{p}^{\prime}$-DDE, respectively, in the minimal salts medium at a concentration of $10 \mathrm{mg} / \mathrm{l}$. The inocula were first extracted by $5 \mathrm{ml}$ hexane and then extracted by $5 \mathrm{ml}$ ethyl acetate; they were centrifugally separated and the organic phase was collected. They were then dehydrated with anhydrous sodium sulfate, the extract was combined, and after drying with a nitrogen blowing instrument, the volume was brought to $5 \mathrm{ml}$ with hexane.

The metabolites were identified using the Clarus 500 GC/MS (PerkinElmer, USA) equipped with an autosampler, a splitless model injector, and an Elite-5MS (PerkinElmer) capillary column (crosslinked 5\% phenyl-95\% methyl silicone, $30 \mathrm{~m} \times 0.25 \mathrm{~mm} \times 0.25 \mu \mathrm{m})$. The initial oven temperature was $70^{\circ} \mathrm{C}(1.0 \mathrm{~min}$ hold $)$ and was increased to $180^{\circ} \mathrm{C}$ at a rate of $20^{\circ} \mathrm{C} / \mathrm{min}(5.0 \mathrm{~min}$ hold). The temperature was then increased by $5^{\circ} \mathrm{C}$ per minute to a temperature of $260^{\circ} \mathrm{C}$. The injector temperatures were maintained at $250^{\circ} \mathrm{C}$. An electron ionization with an electron energy of $70 \mathrm{eV}$ was used. The ion source temperature of the mass spectrometer was $250^{\circ} \mathrm{C}$. The scanning range was from 40 to $550 \mu$. The transfer line temperature was $280^{\circ} \mathrm{C}$.

\section{Statistical analysis}

The degradation of DDE can be calculated as follows:

$$
X=\frac{C_{c k}-C_{x}}{C_{x}}
$$

where $\mathrm{X}$ is the degradation percentage of DDE; $\mathrm{C}_{\mathrm{x}}(\mathrm{mg} / \mathrm{l})$ is the terminal concentration of DDE after adding the strain; and $\mathrm{C}_{\mathrm{ck}}(\mathrm{mg} / \mathrm{l})$ is the concentration of chlorpyrifos in the control. All of the data were analyzed using variance to determine the standard deviation. The SPSS program (version 21.0) was used to determine the differences among all of the groups. Each treatment was performed in triplicate. The level of statistical significance was set at $P<0.05$.

\section{Results}

\section{Characterization of the isolated DDE-degrading bacteria DXZ9}

The microorganisms were isolated from the sludge of the pesticide factory, which was contaminated by DDT with an enrichment culture technique; the culture was regularly transferred to a fresh medium at weekly intervals in a $500 \mathrm{ml}$ Erlenmeyer flask. After many such transfers, the consortium was gradually acclimated to increasing concentrations of DDE from 50 to $100 \mathrm{mg} / \mathrm{l}$, and the individual microbial strains in the acclimated consortium were isolated on solid media by appropriate plating. The strains were then grown with $50 \mathrm{mg} / \mathrm{l}$ of DDE. Six morphologically distinct bacterial strains were isolated from the sample. The biodegradation proportion of DDE by the strain DXZ9 at the $10 \mathrm{mg} / \mathrm{l}$ concentration was 
Citation: Xie H, Zhu L, Wang J, Jiang J, Wang J (2017) Biodegradation of DDE and DDT by Bacterial Strain Stenotrophomonas sp. DXZ9. J Environ Anal Toxicol 7: 496. doi: 10.4172/2161-0525.1000496

Page 3 of 8

over $36.7 \%$ in 5 days. Therefore, the strain DXZ9 was selected for further studies.

The phylogenetic tree of strain DXZ9 based on the 16S rDNA gene sequences analysis and its relationship with other known DDT- and DDE-degraders is shown in Figure 1. A scanning electronic micrograph of the strain is shown in Figure 2. The bacterial strain DXZ9 is short and rod shaped; it has a flagellum but no spores; and it is Gram-positive. Physicochemical and biochemical tests showed that the strain DXZ9 is negative for amylolysis, acetyl methyl alcohol, urea salt, indole, mannitol fermentation, wood sugar fermentation, lactose fermentation, and nitrate reduction and citrate, but positive for catalase. Based on the phenotypic, physiological and biochemical characteristics, and phylogenetic analysis of $16 \mathrm{~S}$ rDNA, the strain DXZ9 was identified to belong to the Stenotrophomonas $s p$. Previous references have demonstrated that Stenotrophomonas sp. could degrade some organic pollutants, such as $\mathrm{HCH}$ and methyl parathion [17], acetamiprid [18] and chlorothalonil [19], but this paper is the first report that the strain Stenotrophomonas sp. could degrade the organochlorine pesticide DDE. Strain DXZ9 has been deposited in the China Center for Type Culture Collection, and its strain number is CCTCCM2013304.

\section{Biodegradation of DDE by strain DXZ9}

Environmental factors such as $\mathrm{pH}$ and temperature in addition to other factors might affect the growth of microorganisms and their degradation abilities. Therefore, the biodegradation character of DDE by strain DXZ9 was investigated. The growth curve of DXZ9 and the degradation curve of DDE on the 3rd, 5th, 7th and 10th days are shown in Figure 3a. From the Figure 3a, the growth amount of DXZ9 reached a maximum on the third day; it then decreased gradually in the culture medium with extension of the culture time. Although the amount of growth was not increased, the strain still exerted degradation and so the degraded proportion of DDE increased. The highest degradation proportion of DDE was $39.4 \%$ on the fifth day, and the difference was significant among the different treatments by an analysis of variance. After 5 days and because of the almost complete demise of the bacterial strain and the reduction of the activity, the degradation curve increased slowly and remained relatively smooth after 7 days. The growth curve was reduced at all times and ultimately smooth.

The effect of $\mathrm{pH}$ on the DDE degradation proportion and the growth curve of DXZ9 within 5 days are shown in Figure $3 \mathrm{~b}$, and the $\mathrm{pH}$ values of the culture medium were 4.0, 5.0, 6.0, 7.0, 8.0, 9.0 and 10.0. In the $\mathrm{pH}$ value range, the effect of $\mathrm{pH}$ on the growth curve of DXZ9 within 5 days was minimal; neutral $\mathrm{pH}$ was optimal for strain DXZ9. In a $\mathrm{pH}$ range of 4.0 7.0, the effect of $\mathrm{pH}$ on the DDE degradation proportion of DXZ9 was definitive. At the acidic condition, the biodegradation proportion was enhanced with increasing $\mathrm{pH}$ and the degradation proportion of DDE was $39.9 \%$ at the neutral condition. At the $\mathrm{pH}$ range of $7.0 \sim 10.0$, the biodegradation proportion was reduced with increasing $\mathrm{pH}$, and the difference was significant among the different $\mathrm{pH}$ conditions as concluded by an analysis of variance. In conclusion, the biodegradation proportion of DXZ9 was higher in the range of 6.0 8.0. Because the $\mathrm{pH}$ value produced an effect on the growth of strain DXZ9 and the activity of its enzyme, the effect of $\mathrm{pH}$ in the initial culture on the DDE degradation proportion was in accordance with the general growth curve.

The initial concentrations of DDE were 1, 5, 10 and $20 \mathrm{mg} / \mathrm{l}$. When inoculating the degrading bacterium DXZ9 and then shaking the culture at $\mathrm{pH} 7.0$ and $30^{\circ} \mathrm{C}$, the growth amount and degrading proportion of DXZ9 was determined after 5 days. The effects of the concentration of DDE on the degradation proportion and growth curve of DXZ9 are

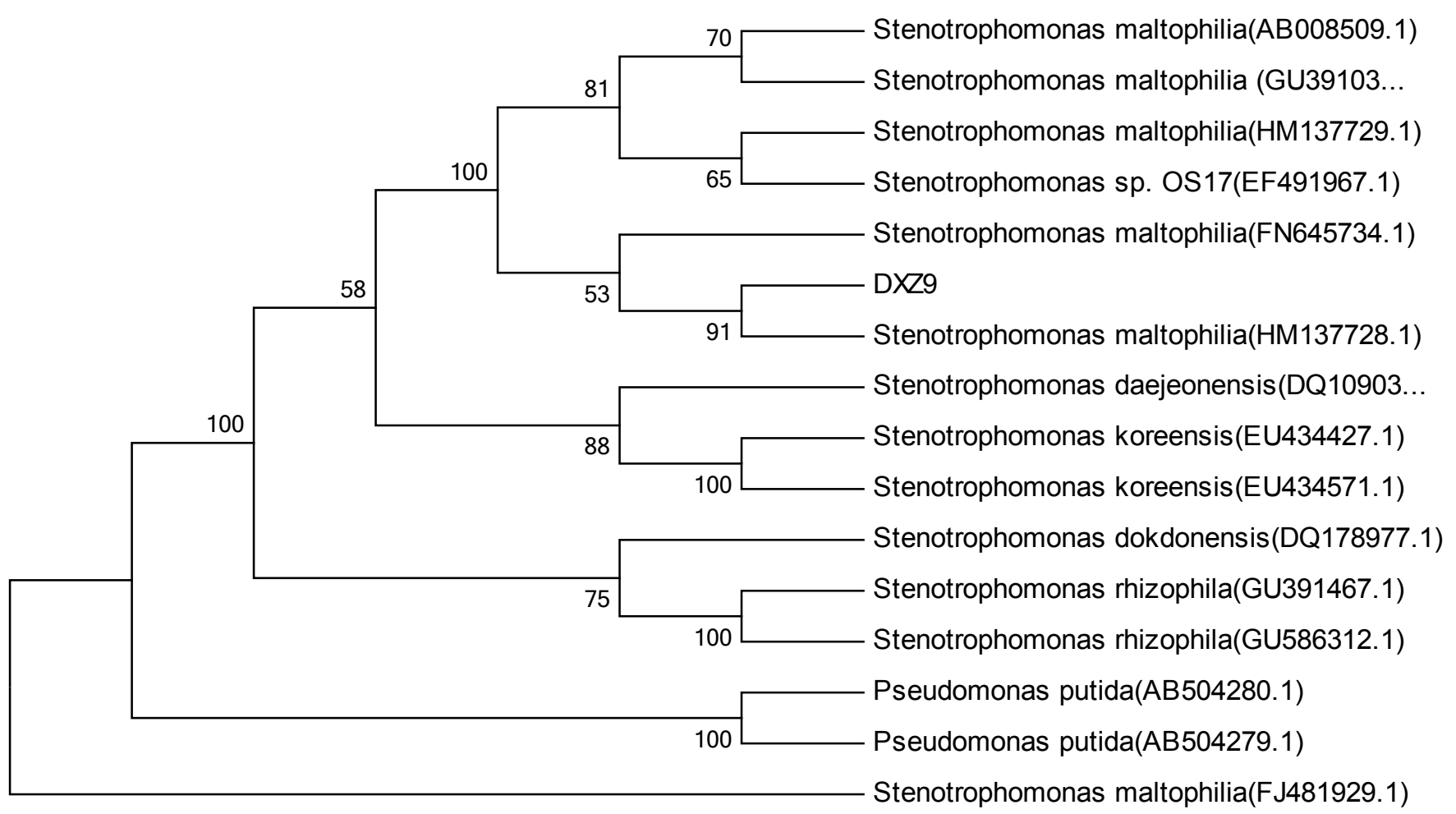

Figure 1: A phylogenetic tree of strain DXZ9 based on the 16S rDNA gene sequences analysis and its relationship with other known DDT and DDE degraders. (The scale bars represent 0.005 substitutions per site). 
Citation: Xie H, Zhu L, Wang J, Jiang J, Wang J (2017) Biodegradation of DDE and DDT by Bacterial Strain Stenotrophomonas sp. DXZ9. J Environ Anal Toxicol 7: 496. doi: 10.4172/2161-0525.1000496

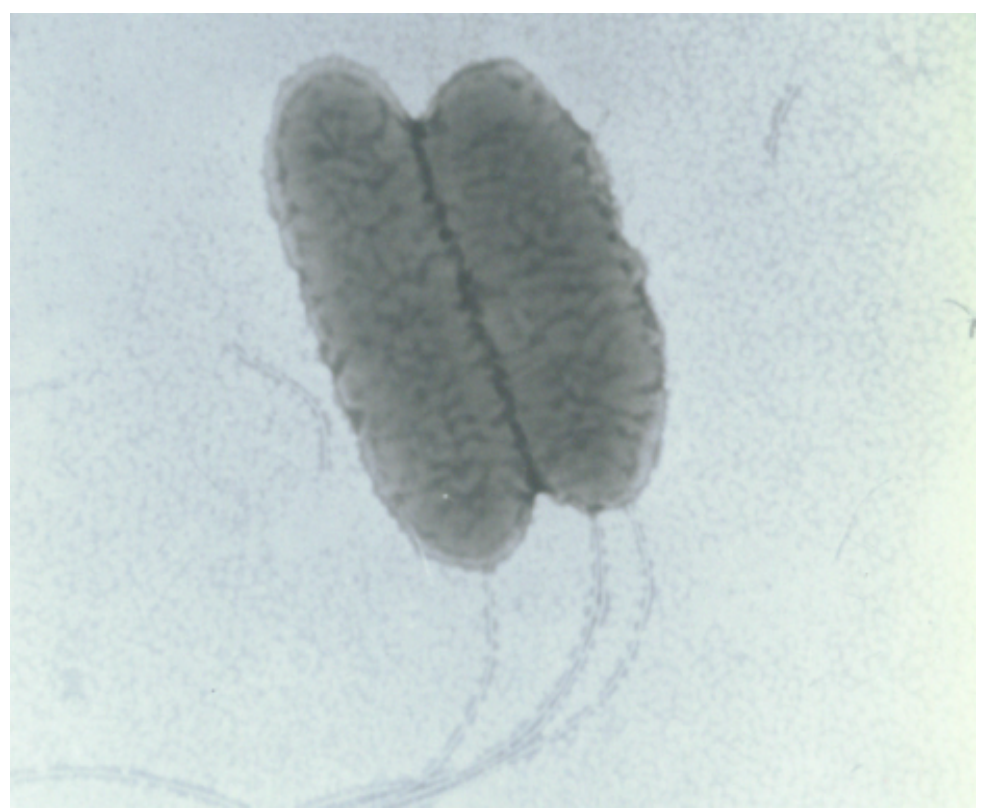

Figure 2: A scanning electronic micrograph of strain of DXZ9 $(80 \times 25)$.
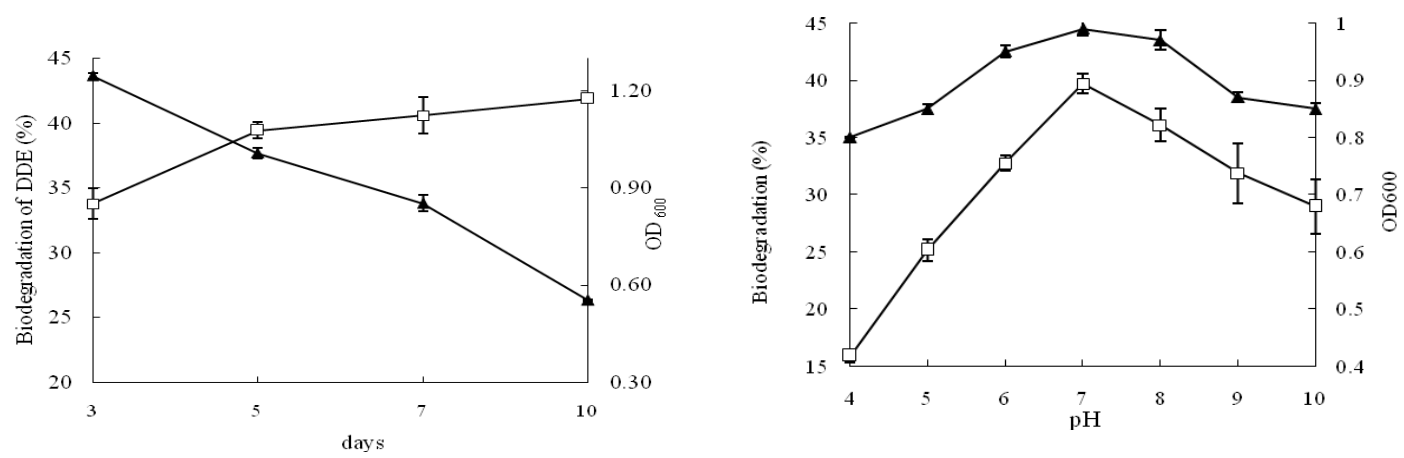

(a)

(b)

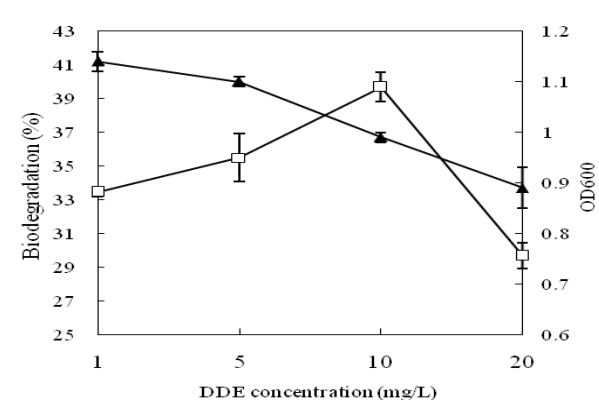

(c)

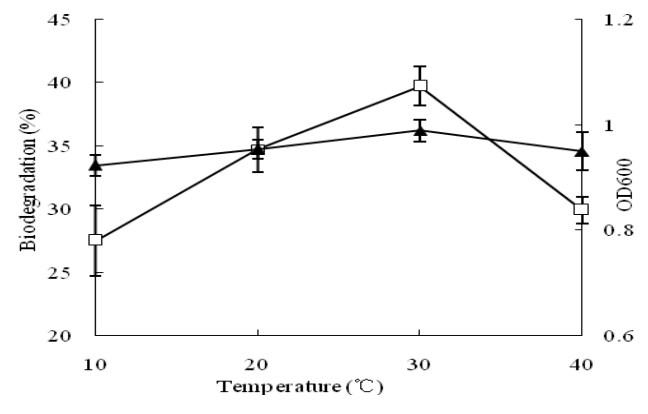

(d)

$\multimap-$ Biodegradation $\longrightarrow$ OD600

Figure 3: Effect of degradation time (a) different $\mathrm{pH}$ values (b), DDE concentrations(c) and temperatures (d) on DDE degradation and bacteria growth within 5 days. Each point represents the mean of three replicates, and the error bars represent the standard deviation (SD). 
Citation: Xie H, Zhu L, Wang J, Jiang J, Wang J (2017) Biodegradation of DDE and DDT by Bacterial Strain Stenotrophomonas sp. DXZ9. J Environ Anal Toxicol 7: 496. doi: 10.4172/2161-0525.1000496

Page 5 of 8

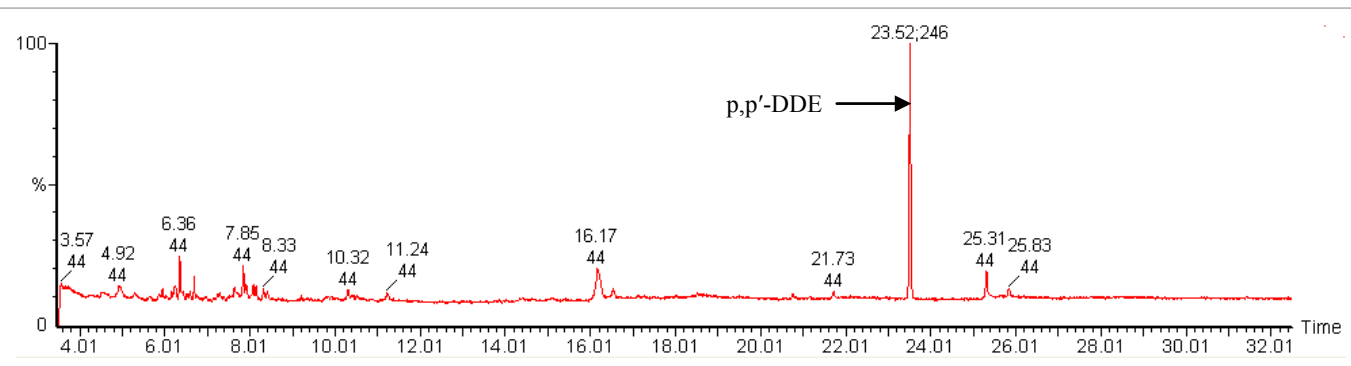

a: the control sample on the tenth day

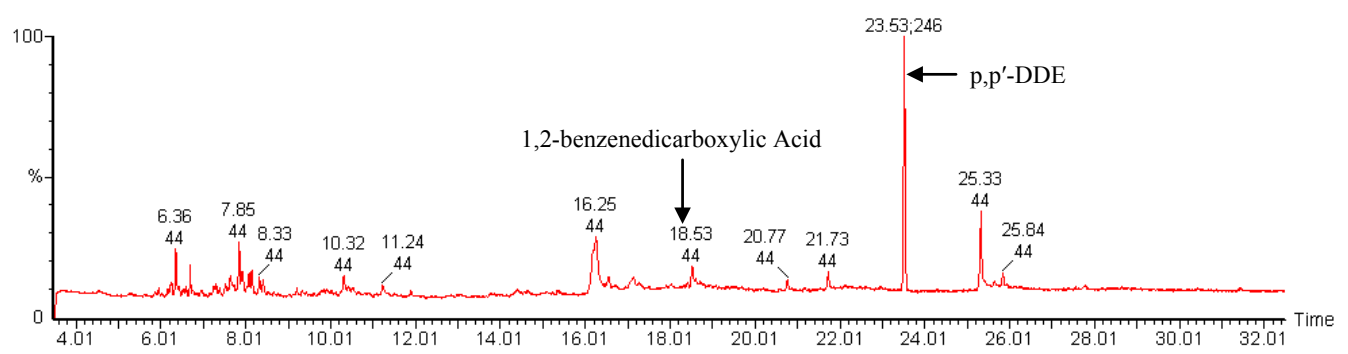

b: the treatment with DXZ9 on the third day

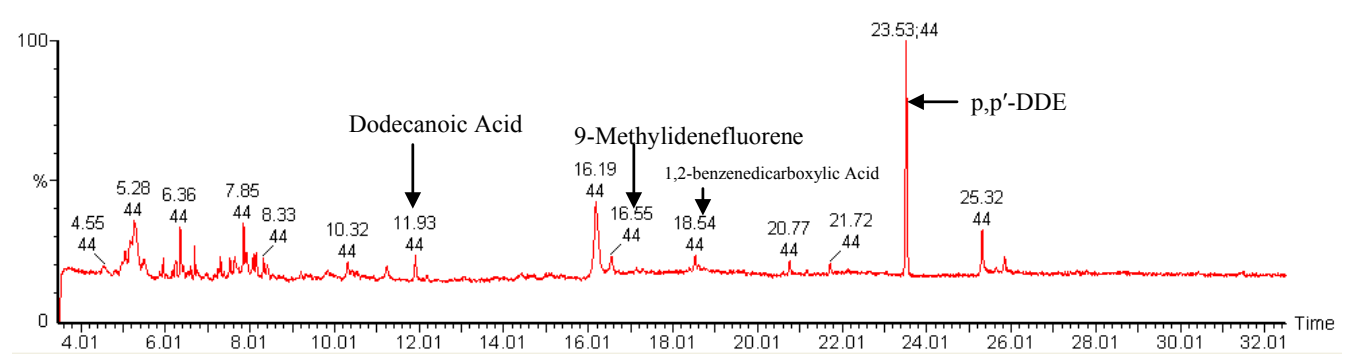

c: the treatment with DXZ9 on the fifth day

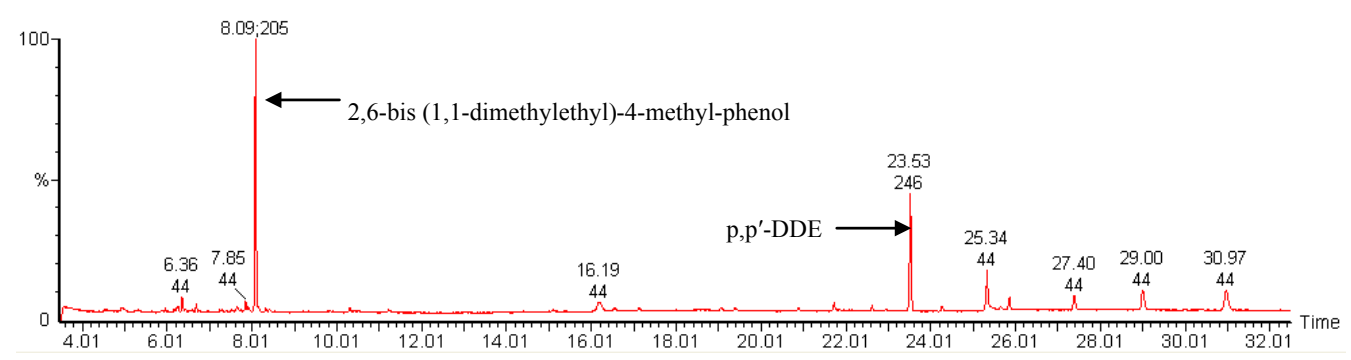

d: the treatment with DXZ9 on the tenth day

Figure 4: Total ion chromatogram of the metabolites of DDE.

shown in Figure 3c. Under the influence of the concentration of DDE, the growth tendency of DXZ9 was identical; the growth of the strain declined along with the increasing concentration of DDE. With the increase of the concentration of DDE, the degraded proportions first increased and then decreased, and the degraded proportion reached $39.7 \%$ at a concentration of $10 \mathrm{mg} / \mathrm{l}$. The degraded proportions began decreasing as the concentration increased. At a concentration of 20 $\mathrm{mg} / \mathrm{l}$, the difference of the degraded proportions was significant in terms of the different initial concentration by an analysis of variance.

The initial concentration of DDE was $10 \mathrm{mg} / \mathrm{l}$, the initial $\mathrm{pH}$ was 7.0 , and the culture temperatures were set to $10,20,30$ and $40^{\circ} \mathrm{C}$. Next, the growth amount and degrading proportion of DXZ9 was determined, and the effects of temperature on the degradation proportion and growth curve of DXZ9 are shown in Figure 3d. Under the influence of temperature, the growth amount of strain DXZ9 has the same tendency as the change of the degraded proportions, and both increased with increasing temperature and reached a maximum at $30^{\circ} \mathrm{C}$. The degraded proportion of DDE was $39.7 \%$, which decreased with increasing temperature. The difference of the degraded proportions is significant among different temperatures as determined by an analysis of variance. Because the culture temperature affected the growth amount of the bacteria, and the growth amount of bacteria affected the degraded proportion of DDE, this tendency is consistent with the characteristics of the microorganism's growth.

\section{Biodegradation of DDT by the strain DXZ9}

In the optimal condition in which the $\mathrm{pH}$, concentration of DDT, and cultivation temperature are $7,10 \mathrm{mg} / \mathrm{l}$ and $30^{\circ} \mathrm{C}$, respectively, 
Citation: Xie H, Zhu L, Wang J, Jiang J, Wang J (2017) Biodegradation of DDE and DDT by Bacterial Strain Stenotrophomonas sp. DXZ9. J Environ Anal Toxicol 7: 496. doi: 10.4172/2161-0525.1000496

Page 6 of 8

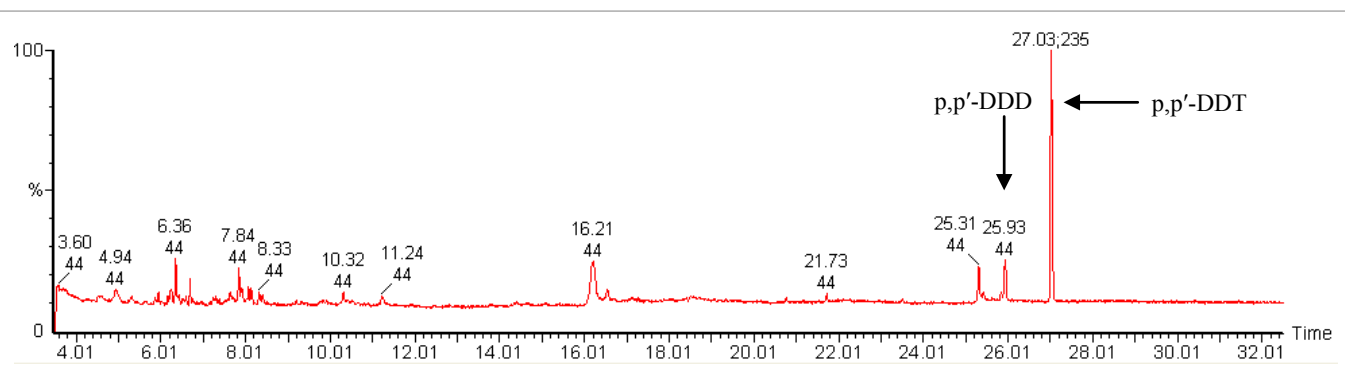

a: the control sample on the tenth day

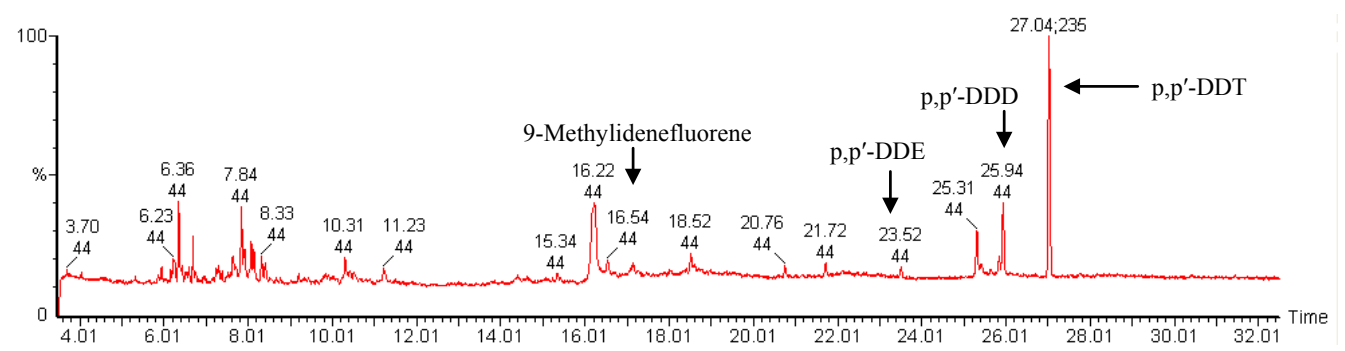

b: the treatment with DXZ9 on the third day

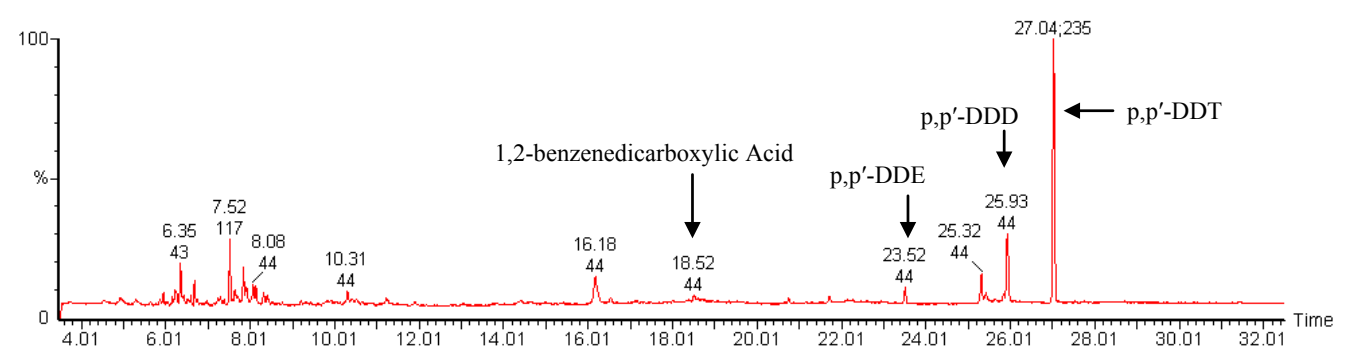

c: the treatment with DXZ9 on the fifth day

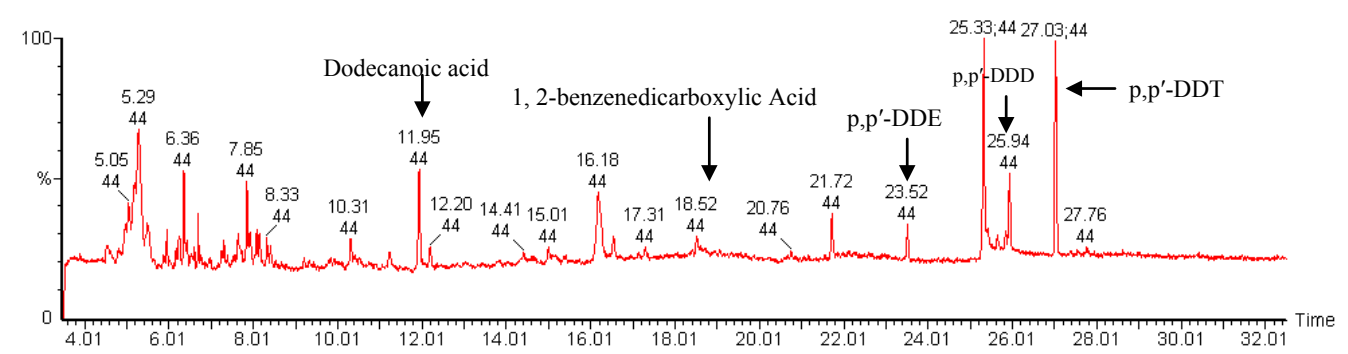

d: the treatment with DXZ9 on the tenth day

Figure 5: Total ion chromatogram of the metabolites of DDT.

within 5 days based on the experimental optimization, the degradation proportion of DDT was $55.0 \%$.

\section{Confirmation of metabolites}

The biodegradation of metabolites was determined based on a search of the MS library and GC-MS analysis (Figures 4 and 5). Figure 5 as shown in the control sample on the tenth day, showed that DDT is naturally and reductively dechlorinated to DDD, and DDE was not detected. The result showed that DDT is dehydrochlorinated to DDE under the action of the bacterial strain DXZ9, but the metabolites of DDE were not identified. However, many substances were detected, and these substances were not determined to be metabolites of DDE after careful analysis. Some literature reported that DDE is dechlorinated to DDMU [23,24]. DDMU was not detected in this experimental condition. Perhaps the degradation products of DDE are multiple undefined substances; this idea has been proposed for further study.

\section{Discussion}

\section{DDT- and DDE-degrading microorganisms}

Previous publications indicate that multiple microorganisms could degrade DDT by the co-metabolism mode, and the co-metabolic degradation of DDT and DDE is involved in the utilization of growth substitution and the substitution specificity of degraded enzymes [25]. Previous literature has indicated that microorganisms might have a powerful enzymatic system that is responsible for the degradation of pollutants [26], but various microorganisms require a different substrate to metabolize pollutants. The results of the present research further confirmed the prevalence of co-metabolism in pollutant degradation 
Citation: Xie H, Zhu L, Wang J, Jiang J, Wang J (2017) Biodegradation of DDE and DDT by Bacterial Strain Stenotrophomonas sp. DXZ9. J Environ Anal Toxicol 7: 496. doi: 10.4172/2161-0525.1000496

Page 7 of 8

by microorganisms. Nadeau [20] showed that Alcaligenes eutrophus A5 oxidizes DDT with PCB as the substrate, and Hay [14] reported that Pseudomonas acidovorans M3GY could degrade DDE, which is grown on biphenyl. Furthermore, Pseudomonas species [27] was isolated from insecticide contaminated soil by a biphenyl enrichment culture, which was capable of degrading DDT. The bacterial strain Alcaligenes denitrificans [28] could accelerate the degradation of DDE by adding $1 \mathrm{~g} / \mathrm{l}$ of glucose, and the strain KK could co-metabolize DDT to DDE with $0.5 \%$ glucose in the culture [22]. The bacterial strain Alcaligenes denitrificans IRTC-4 could metabolize DDT under both aerobic and anaerobic conditions and was further enhanced by $50.0 \%$ in the presence of $1.0 \mathrm{~g} / \mathrm{l}$ of glucose [29]. Cladosporium sp. fungus strain $\mathrm{AJR}^{3} 18501$ could degrade DDT by utilizing potato dextrose broth as a substitution [30].

In the present study, the strain DXZ9 was identified as belonging to the Stenotrophomonas sp., and it is different from those microorganisms previously reported in the literature that could degrade DDE. The degradation mechanism of DDE is generally co-metabolism, and different strains require different substrates, such as glucose and biphenyl, and the substrate of the strain DXZ9 is peptone. The strain DXZ9 could degrade DDE by co-metabolism in the presence of peptone, and the degradation proportion of DDE was $39.4 \%$ at the end of 5 days. The proportion increased slightly and reached $41.9 \%$ at the end of 10 days. Moreover, not only DDE but also its parent material (DDT) could be degraded by this strain. The optimal growing conditions were optimized, and the optimal initial conditions included a $\mathrm{pH}$ of 7 , a substrate concentration of $10 \mathrm{mg} / \mathrm{l}$, and a cultivation temperature of $30^{\circ} \mathrm{C}$. Within 5 days, the degradation proportion of DDT was $55.0 \%$ under these optimal conditions.

\section{Degraded mechanism of DDT and DDE by microbial degradation}

There were some reports regarding the metabolic pathway of DDT, and a number of these concerning DDT metabolism by microorganisms were discussed. From this research, it was determined that the dominant reaction was dehydrochlorination of DDT to DDE, which is predominant under aerobic conditions, whereas there is a reductive dechlorination to DDD under anaerobic conditions $[31,32]$. Some researchers believed that DDE could not further degrade but that it could be metabolized into DDMU by reductive dechlorination with methanogens and biological sulfide available in the submarine sediment $[23,24]$. DDE could be degraded by the dechlorination enzymes, dioxygenase and hydrolase in the appropriate conditions [33]. Sari [25] reported that dioxygenase and lignin peroxidase levels were higher with the addition of DDT, and these two enzymes play important roles in the degradation of DDT. Further research is needed to prove whether the extracellular enzyme or intracellular enzyme systems take part in the process of DDE degradation and confirm the type of enzymes in our prospective study. The further metabolism of DDE could mostly continue under aerobic conditions because there is a double bond structure of the relative instability in the molecule of DDE, and DDE is able to undergo oxidation [34]. In this research, DDT is dehydrochlorinated to DDE first by this strain, but the metabolites of DDE are not identified. Previous studies have also reported that the fungal strain Fusarium solani was able to metabolize DDT, DDD and DDE in the soil, but its products were not clear [35].

There are some reports regarding the metabolic system of DDE, in which the degradation gene of DDE was studied. The bphAaAbAcAdBC genes in the TYM3221 are involved in DDE degradation, and they are regulated by the bphST-coded two-component regulatory system [16]. The enzyme and regulatory genes responsible for the initial steps of DDE degradation in TYM3221 were characterized to elucidate the bacterial enzyme system involved in the aerobic degradation of DDE, and they provided a molecular biological basis for revealing the regulation mechanism of degradation bacteria of DDT and DDE. This result provides a theory for the biological treatment of the pollutants and the bioremediation of the polluted environment.

\section{Evaluation of the detoxification of pesticides by biodegradation}

Because there are possibly toxic intermediate products during the biodegradation of pesticides, an evaluation criterion of biodegradation was not utilized when measuring the reduction of pesticides; thus, the chemical structure and toxicity of intermediate products that should be taken into account. The toxicity of the degradation product of the pollutants should be confirmed by the experiment. Su [36] reported the toxicity test of the degradation product of Atrazine by a micronucleus test of the root tip (Vicia faba). Kong [37] studied the toxic bioassay of the degrading product of endosulfan through the coelomocyte of the earthworm by single cell gel electrophoresis (SCGE) by measuring the soil microbial biomass carbon and enzymatic activities. The detoxification of endosulfan by the JBW4 strain was evaluated, and it has been verified that the genotoxicity and ecotoxicity of endosulfan in the soil were effectively reduced after biodegradation by the JBW4 strain. The detoxification of DDE by the DXZ9 strain has been researched in our laboratory with a pot experiment simulating bioremediation; the results are presented in another paper.

\section{Conclusions}

A bacterial strain capable of degrading DDE and its parent compound were simultaneously isolated from the sludge from the pesticide factory, which was contaminated with DDT by an enrichment culture technique, and identified as a Stenotrophomonas $s p$. The results showed that the Stenotrophomonas sp. DXZ9 not only has the ability to metabolize DDE but also to degrade its parent compound, and the result showed that DDT is dehydrochlorinated to DDE under the action of the bacteria DXZ9, and the metabolites of DDE are multible undefinedsubstances.

\section{Acknowledgements}

This study was supported by grants from the National Natural Science Foundation of China (Nos. 41671321, 41071164, 21377075 and 41001152) and National key research and development project of China (2016YFD0800304).

\section{Author Contributions}

Conceived and designed the experiments: Lusheng Zhu. Performed the experiments: Jinhui Jiang, Hui Xie. Analyzed the data: Hui Xie, Jinhui Jiang, Contributed to the writing of the manuscript: Hui Xie. Critically revised: Jun Wang, Jinhua Wang.

\section{References}

1. Vanden Berg H (2009) Global status of DDT and its alternatives for use in vector control to prevent disease. Environmental Health Perspectives 117: 1656-1663.

2. Hu WY, Lu YL, Wang TY, Luo W, Shi YJ, et al. (2010) Spatial variability and temporal trends of $\mathrm{HCH}$ and DDT in soils around Beijing Guanting Reservoir, China. Environmental Geochemistry and Health 32: 441-449.

3. Hu WY, Huang B, Zhao YC (2014) Distribution, sources and potential risk of $\mathrm{HCH}$ and DDT in soils from a typical alluvial plain of the Yangtze River Delta region China. Environmental Geochemistry and Health 36: 345-358.

4. Syed JH, Malik RN (2011) Occurrence and source identification of organochlorine pesticides in the surrounding surface soils of the Ittehad Chemical Industries Kalashah Kaku, Pakistan. Environment Earth Science 62: 1311-1321. 
Citation: Xie H, Zhu L, Wang J, Jiang J, Wang J (2017) Biodegradation of DDE and DDT by Bacterial Strain Stenotrophomonas sp. DXZ9. J Environ Anal Toxicol 7: 496. doi: 10.4172/2161-0525.1000496

Page 8 of 8

5. Mercado LA, Freille SM, Vaca-Pereira JS, Cuellar M, Flores L, et al. (2013) Serum concentrations of $p, p^{\prime}$-dichlorodiphenyltrichloroethane ( $\left.p, p^{\prime}-D D E\right)$ in a sample of agricultural workers from Bolivia. Chemosphere 91: 1381-1385.

6. Cárdenas-González M, Gaspar-Ramírez O, Pérez-Vázquez FJ (2013) p,pDDE, a DDT metabolite, induces pro inflammatory molecules in human peripheral blood mononuclear cells "in vitro". Experimental and Toxicologic Pathology 65: 661-665.

7. Nguyen PAT, Sato Y, Iwasaki T, Miyauchi K, Tokudac M, etal. (2011)Characterization of the 1,1-dichloro-2,2-bis(4-chlorophenyl) ethy degradation system in Janibacter sp. TYM3221. Enzyme and Microbial Technology 49: 532-539.

8. Bao P, Hu ZY, Wang XJ, Chen J, Ba YX, et al. (2012) Dechlorination of p,pDDTs coupled with sulfate reduction by novel sulfate-reducing bacterium Clostridium sp. BXM. Environmental Pollution 162: 303-310.

9. Wang GL, Bi M, Liang B (2011) Pseudoxanthomonas jiangsuensis sp. Nov., a DDT-degrading bacterium isolated from a long-term DDT-polluted soil. Current Microbiology 62: 1760-1766.

10. Xiao PF, Mori T, Kamei I, Kondo R (2011) A novel metabolic pathway for biodegradation of DDT by the white rot fungi, Phlebia lindtneri and Phlebia brevispora. Biodegradation 22: 859-867.

11. Thomas JE, Gohil H (2011) Microcosm studies on the degradation of o,p'and $p, p^{\prime}-D D T$, DDE, and DDD in a muck soil. World Journal of Microbiology \& Biotechnology 27: 619-625.

12. Suhara H, Adachi A, Kamei I, Maekawa N (2011) Degradation of chlorinated pesticide DDT by litter-decomposing basidiomycetes. Biodegradation 22: 1075 1086.

13. Bumpus JA, Powers RH, Sun T (1993) Biodegradation of DDE (1,1-dichloro2,2-bis(4-chlorophenyl)ethene) by phanerochaete chrysosporium. Mycological Research 97: 95-98.

14. Hay AG, Focht DD (1998) Cometabolism of 1, 1-dichloro-2, 2-bis (4-chlorophenyl) ethylene by Pseudomonas acidovorans M3GY grown on biphenyl. Applied and Environmental Microbiology 64 (6): 2141-2146.

15. Aislabie J, Davison AD, Boul HL, Franzmann PD, Jardine DR, et al. (1999) Isolation of Terrabacter sp. strain DDE-1, which metabolizes 1,1-dichloro2,2-bis(4-chlorophenyl)ethylene when induced with biphenyl. Applied and Environment Microbiology 65: 5607-5611.

16. Nguyen PAT, Trinh THT, Fukumitsu Y, Shimodaira J, Miyauchi K, et al. (2013) Gene cluster and regulation system for 1,1-dichloro-2,2-bis(4-chlorophenyl) ethylene (DDE) degradation in Janibacter sp. TYM3221. Journal of Bioscience and Bioengineering 116: 91-100.

17. Zhang H, Yang C, Zhao Q, Qiao CL (2009) Development of an autofluorescent organophosphates-degrading Stenotrophomonas sp. with dehalogenase activity for the biodegradation of hexachlorocyclohexane $(\mathrm{HCH})$. Bioresource Technology 100: 3199-3204.

18. Tang HZ, Li J, Hu HY (2012) A newly isolated strain of Stenotrophomonas sp. hydrolyzes acetamiprid, a synthetic insecticide. Process Biochemistry 47: 1820-1825.

19. Zhang MY, Teng Y, Zhu Y (2014) Isolation and characterization of chlorothalonildegrading bacterial strain $\mathrm{H} 4$ and its potential for remediation of contaminated soil. Pedosphere 24: 799-807.

20. Nadeau LJ, Menn FM, Breen A, Sayler GS (1994) Aerobic degradation of 1,1,1-trichloro-2,2-bis (4-chlorophenyl) ethane (DDT) by Alcaligenes eutrophus A5. Applied and Environment Microbiology 60: 51-55.

21. Dong XZ, Cai MY (2001) Common bacterial System Identification Manual. Beijing Science Press.
22. Xie H, Zhu LS, Xu QF, Wang J, Liu W, et al. (2011) Isolation and degradation ability of the DDT-degrading bacterial strain KK. Environment Earth Science 62: 93-99.

23. Quensen JF, Mueller SA, Jain MK, Tiedje JM (1998) Reductive Dechlorination of DDE to DDMU in Marine Sediment Microcosms. Science 280: 722-724.

24. Quensen lii JF, Tiedje JM, Jain MK, Mueller SA (2001) Factors controlling the proportion of DDE dechlorination to DDMU in Palos Verdes margin sediments under anaerobic conditions. Environment Science Technology 35: 286-291.

25. Sari AA, Tachibana S, Itoh K (2012) Determination of co-metabolism for 1,1,1-trichloro-2,2-bis(4-chlorophenyl) ethane (DDT) degradation with enzymes from Trametes versicolor U97. Journal of Bioscience and Bioengineering 114: 176-181.

26. Verma A, Ali D, Farooq M, Pant AB, Ray RS, Hans RK (2011) Expression and inducibility of endosulfan metabolizing gene in Rhodococcus strain isolated from earthworm gut microflora for its application in bioremediation. Bioresource Technology 102: 2979-2984.

27. Kamanavalli CM, Ninnekar HZ (2004) Biodegradation of DDT by a Pseudomonas Species. Current Micrbiology 48: 10-13.

28. Ahuja R, Awasthi N, Manickam N, Kumar A (2001) Metabolism of 1,1-dichloro2,2-bis(4-chlorophenyl)ethylene by Alcaligenes denitrificans. Biotechnology Letters 23: 423-426.

29. Ahuja R, Kumar A (2003) Metabolism of DDT [1,1,1-Trichloro-2,2-bis(4chlorophenyl) ethane] by Alcaligenes denitrificans ITRC-4 under aerobic and anaerobic conditions. Current Microbiology 46: 65-69.

30. Juhasz AL, Naidu R (1999) Apparent degradation of 1,1,1-trichloro-2,2-bis(pchlorophenyl) ethane (DDT) by a Cladosporium sp. Biotechnology Letters 21 : 991-995.

31. Johnsen RE (1976) DDT metabolism in microbial systems. Residue Reviews 61: 1-28.

32. Lal R, Saxena DM (1982) Accumulation, metabolism and effects of organochlorine insecticides on microorganisms. Microbiology Reviews 46: 95-127.

33. Thomas JE, Ou LT, Abid AA (2008) DDE remediation and degradation. Reviews of Environmental Contamination and Toxicology 194: 55-69.

34. Corona-Cruz A, Gold-Bouchot G, Gutierrez-Rojas M, Monroy-Hermosillo O Favela E (1999) Anaerobic-Aerobic Biodegradation of DDT (Dichlorodiphenyl Trichloroethane) in Soils. Bulletin of Environmental Contamination and Toxicology 63: 219-225.

35. Mitra J, Mukherjee P, Kale S (2001) Bioremediation of DDT in soil by genetically improved strains of soil fungus Fusarium solani. Biodegradation 12: 235-245.

36. Su J, Zhu LS, Li XH (2010) Effects of nitrogen and phosphorus fertilizer on atrazine degradation and detoxification by degrading strain HB-5. Environmental Science (in Chinese) 31: 210-215.

37. Kong LF, Zhu SY, Zhu LS, Xie H, Wei K, et al. (2014) Colonization of Alcaligenes faecalis strain JBW4 in natural soils and its detoxification of endosulfan. Applied Microbiology and Biotechnology 98: 1407-1416. 